\title{
O VATICANO EM ROMA RECOMENDA FERRO NUXADO: DISCURSO E ANÁLISE DE UM ANÚNCIO DE MEDICAMENTO DO INÍCIO DO SÉCULO XX
}

\author{
Samanta Rosa Maia* \\ Universidade Federal de Santa Catarina \\ Centro de Comunicação e Expressão \\ Florianópolis, SC, Brasil
}

\begin{abstract}
Resumo: Este trabalho adota como referência teórica a Análise do Discurso de filiação francesa, praticada por Eni Orlandi, e propõe a análise de um texto intitulado O Vaticano em Roma recomenda Ferro Nuxado, publicado em uma revista de grande circulação do início do século $X X$. $O$ objetivo do trabalho foi trazer à tona as ideologias subjacentes à linguagem publicitária no início do século $X X$ e, ao mesmo tempo, fornecer um exemplo prático e didático de análise, que notabilizasse os aspectos linguístico, ideológico e, principalmente, histórico do discurso. Para tal, a metodologia adotada foi a analítica, aplicada a um corpus constituído de um único texto e baseada nos conceitos apresentados por Orlandi, principalmente em Análise de discurso: princípios e procedimentos (1999).
\end{abstract}

Palavras-chave: Discurso. Publicidade. Século XX.

1 INTRODUÇÃO

Cabe dizer, primeiramente, a partir do que Eni Orlandi apresenta, em Análise do discurso: princípios e procedimentos (1999), como sendo o segundo momento do gesto interpretativo (o qual trata do próprio analista e seu envolvimento na interpretação do objeto), que minha relação com o objeto simbólico analisado nesse artigo se deu por meio de uma pesquisa em periódicos de época para a dissertação de Mestrado, que, por sua vez, se estendeu pelos anos seguintes para o projeto de Doutorado. Compartilhando dos pressupostos teóricos da pesquisadora a respeito da dimensão social da linguagem, quando afirma, por exemplo: “A Análise de Discurso que pratico leva a sério a afirmação de Saussure de que a língua é fato social. Pensamos a língua como fato e significamos o que é social, ligando a língua e a exterioridade, a língua e a ideologia, a ideologia e o inconsciente" (ORLANDI, 2003, p. 3), o trabalho assim justifica-se e assume essa corrente para efetuar a análise pretendida.

Como requisito para a realização da análise proposta adotou-se a escolha de um "objeto" que fosse representativo em relação à questão de o texto ser um objeto, além de evidentemente linguístico, evidentemente histórico. Conforme Orlandi (1995), é a

\footnotetext{
* Doutoranda do Programa de Pós-Graduação em Literatura da Universidade Federal de Santa Catarina (UFSC), membro do Núcleo de Pesquisas em Informática, Literatura e Linguística (NuPILL) e bolsista CNPq. Email: samantamaia9@gmail.com
} 
dimensão histórica do texto que lhe confere o caráter de discurso: "o texto é um objeto histórico. Histórico aí não tem o sentido de ser o texto um documento, mas um discurso" (1995, p. 112). Todo texto é histórico, todo texto insere um conceito de tempo no seu discurso e está inserido em um conceito de tempo, isto é, manifesta-se como interpretação de um tempo, ao passo que também é permeado por ele, reinterpretado; é discurso nas duas vias: árvore e fruto. Qualquer texto, nesse sentido discursivo, não material ou documental, poderia, portanto, servir à análise do discurso e a este trabalho, entretanto, a escolha de um "objeto" não contemporâneo, distante quase um século do momento de confecção deste trabalho, pretende tornar patente, até com certo didatismo, a relação língua-ideologia, o aspecto histórico - a historicidade -, o interpretativo, discursivo e, sobretudo, processual, que compõe o texto e nos quais se assenta a análise de discurso de filiação francesa, estudada e desenvolvida, no Brasil, por Eni Orlandi. O objetivo da adoção deste critério é o de mostrar que o foco da análise de discurso não está no objeto em si (por isso a menção entre aspas, no início deste parágrafo), pois ele não se esgota na materialidade linguística, mas no "processo discursivo do qual ele é parte" (ORLANDI, 2013, p. 4):

\begin{abstract}
Ao longo do meu trabalho tenho colocado já repetidas vezes que um texto, do ponto de vista de sua apresentação empírica, é um objeto com começo, meio e fim, mas que se o considerarmos como discurso, reinstala-se imediatamente sua incompletude. Dito de outra forma, o texto, visto na perspectiva do discursivo, não é uma unidade fechada - embora, como unidade de análise, ele possa ser considerado uma unidade inteira - pois ele tem relação com outros textos (existentes, possíveis ou imaginários), com suas condições de produção (os sujeitos e a situação), com o que chamamos sua exterioridade constitutiva (o interdiscurso: a memória do dizer). (ORLANDI, 1995, p. 112-113)
\end{abstract}

Por fim, como segundo requisito para empreender esta análise está a opção por empregar os termos cunhados por Orlandi, principalmente, em Análise do discurso: princípios e procedimentos (1999), para dirigir a análise do discurso, no caso, publicitário, de um anúncio do início do século XX, visando compreender como o texto produz sentido, o que "implica tanto compreender como os sentidos estão nele quanto como ele pode ser lido" (ORLANDI, 1995, p. 117), e como a Análise do Discurso permite essa compreensão. A opção por adotar esse livro como referência principal se deu por considerar que, nele, a autora explicita as noções básicas que compõem o dispositivo teórico da Análise do Discurso sem perder de vista (ou, até, privilegiando) o corpus de análise como resultado de uma construção do pesquisador.

\title{
2 PERIODISMO E DISCURSO PUBLICITÁRIO, MEDICINAL E CIENTIFICISTA
}

O objeto sobre o qual me deterei é um anúncio publicitário publicado na página 10 da revista paulistana A Cigarra, n. ${ }^{\circ}$ 170, datada de 15 de outubro de 1921 (ver: figura 1), juntamente com A Vida Moderna, uma das revistas de variedades de maior circulação em São Paulo no início do séc. XX (CRUZ, 2000, p. 157). Constituem sua condição de produção as relações de força projetadas por um período (o que é exterior à língua) em que as empresas jornalísticas haviam já se consolidado, em que os equipamentos e as 
técnicas de impressão eram cada vez mais sofisticados, e em que os empreendimentos publicitários começavam a florescer. Equipamentos mais modernos possibilitavam uma tiragem e circulação muito maior dos periódicos, ainda que o Brasil tivesse quase $80 \%$ da população analfabeta - disso vê-se que revistas como A Cigarra eram, então, destinadas a uma elite letrada, e inicialmente feminina. De acordo com Cruz (2000), é no início do século XX que a leitura das propagandas "aparece como ocupação típica do passageiro de bonde", ao lado da leitura do jornal, da revista e do livro. Foi nos reclames que os fabricantes e comerciantes de São Paulo, agentes de um mercado em acelerado desenvolvimento de uma metrópole em formação, encontraram o "espaço de visibilidade para seus produtos e serviços" (CRUZ, 2000, p. 153), nos quais se especializariam as revistas de variedades, como a A Cigarra, em que "a linguagem publicitária encontraria seu espaço mais sistemático de afirmação” (CRUZ, 2000, p. 157).

Esse mesmo anúncio encontra-se também em periódicos de países vizinhos ao Brasil, como a Colômbia, e em periódicos norte-americanos (ver: Anexo), de onde foi traduzido (não integralmente). O produto anunciado é um suposto medicamento, chamado "Ferro nuxado", sobre cuja composição não há esclarecimento - o anúncio limita-se a dizer que o "remédio" "contém ferro orgânico" e "um produto terapêutico de extraordinárias qualidades" não-especificado. Também não é informada a posologia ${ }^{1}$, nem a natureza do produto (se se trata de um medicamento, de um complexo vitamínico, de um estimulante).

O fato de não haver nenhuma fiscalização sobre as práticas farmacêuticas, em geral artesanais e sem qualquer regulamentação, contribuía para que produtos de composição misteriosa, acompanhados de promessas milagrosas de prevenção e cura fossem anunciados e vendidos. O próprio nome do produto é propositalmente indecifrável, haja vista que o adjetivo "nuxado", que qualifica o substantivo "ferro", não está dicionarizado, nem no português, tampouco no inglês. $\mathrm{O}$ termo parece, antes, imitar, em sonoridade, $\mathrm{o}$ nome de algum composto químico.

A palavra vigilância sanitária foi mencionada pela primeira vez num documento do governo em 31 de janeiro de 1923, no Regulamento sanitário federal; ainda assim, nenhum dos 1679 artigos do decreto referia-se especificamente à fiscalização da propaganda de remédios: "a medida colaborou para que certos elixires e "tônicos caseiros" fossem sumindo das farmácias. A questão é que, ao fazê-lo, acabariam cedendo ainda mais espaço aos medicamentos vindos da Europa e Estados Unidos." (BUENO; TAITELBAUM, 2008, p. 61). A empresa "GLOSSOP \& C.", depositária no Brasil do "Ferro nuxado", era estadunidense, e atuou no país pelo menos até 1949 (de acordo com o Registro no Diário Oficial da União), como indústria comercial e importadora (comercializando máquinas de malharia, acessórios para teares e tecelagem, umidificadores centrífugos, batedeiras de matéria plástica, indicadores de temperatura, pinos para penteadeiras, peças para máquina de cortar tecidos, etc.). Somente em 1954 pôde efetivar-se a criação de um laboratório, no Brasil, que realizasse análises e estabelecesse padrões de controle para os medicamentos - o Laboratório Central de Controle de Medicamentos (RJ) -, e somente em 1976 houve regulamentação no sentido de controlar a veiculação de propagandas de remédio, quando passou a ser exigida autorização do ministério da saúde para a publicação dos anúncios.

\footnotetext{
${ }^{1}$ Modo como o medicamento deve ser administrado. 


\section{Figura 1 - Publicidade do Ferro Nuxado}

\section{(2) \\ - Vaticano em Roma Recommenda Ferro Nuxado}

Ferro Nuxadas CONTEM FERRO ORGANICO COMO O FERRO DO PROPRIO SANGUE e como o contido em certos alimentos vegetaes.

FERRO NUXADO, contem tanbem um producto therapeutico de extraordinarias qualidades, levado á attenção da Academia Franceza de Medecina pelo celebrado dr. Robin, o qual representa o principal constituinte chimico da forca activa e nervosa, PARH NUTRIR OS NERVOS, de modo que FERRO NUXADO 6 um alimento tanto para o SHNGUE como para os NERVOS.

Ha no corpo humano cerca de... 30.000 .000 .000 .000 globulos vermelhos e cada um d'elles necessita ferro organico para subsistir e produzir energia.

Pode-se hoje dizer que om cada tres pessoas uma padece de falta de robuspessoas uma padece de lalta de robusdevido a varias causas adquiridas ou herdadas, de forma que mesmo uma bôa alimentação ñ̃o the da a proporpão de lerro organico que o organismo requér para o desgastamento ordinario esta mesma condičăo impede systema de extrahir sulficiente nutriçăo dos proprios alimentos.

FERRO É O ELENENTO VITRL DO SHNGUE E O SHNGUE E VIDH. Quando, por consequencia d'esse esgotamento do ferro no sangue, se levanta V. Sa. cansado todos cs dias; se torna lacilmente nervoso, irritavel e desequilibrado: quando os seus trabalhos intellectuaes o deixam acabrunhado no fim do dia: quando a sua digestão se acha descomposta ou sente dores nas espaldas, perda de alento, palpitacóes no coração ou se torna pallido $e$ abatido, näo espere até que a sua saude se perca por completo e venha a prostração nervosa ou que da sua debilidade provenha uma grave enfermidade. Tome FERRO NUXADO - ferro organico - por uma temporada e veja como the enriquece o sangue $e$ the da nova vitalidade. Milhares de pessoas tôm augmentado $\mathrm{em}$ duas semanas a sua robustez, a sua energia e resistencia d'uma forma surprehandente. Deve por $\mathrm{m}$ assegurar-se em tomar FERRO por $m$ assegurar-se em tomar FERRO
NUXADO (ferro organico) e nảo ferro metalico, que muitos medicamentos anantiquados conteem e que um ele. mento inteiramente distincto do FERRO NUXADO. Fiste representa ferro organico em uma forma altamente concentrada; como se se tomar extracto de carne em vez de uma grande quantidade da mesma carne.
Se V. S. está com falta de robustez ou depressão mental; sentindo-se debil, nervoso ou irritavel, ponha á prova o "Ferro Nuxado".

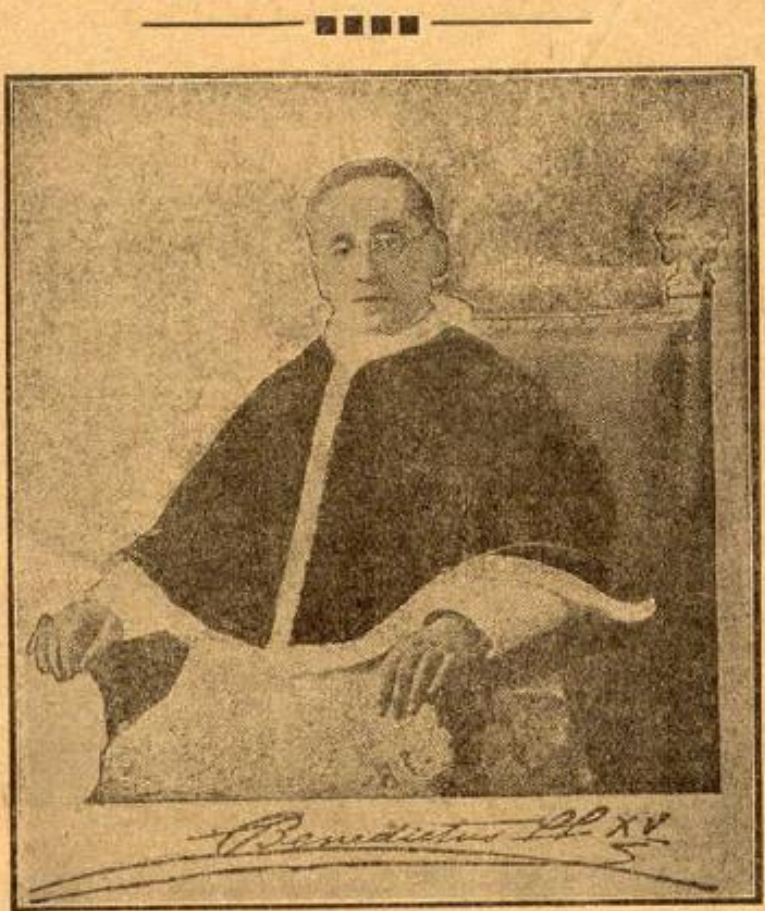

\section{0 que diz o vaticano sobre o "Ferro Nuxado,}

(Traducçato)

Tenho o prazer de informar que o seu presente de Ferro Nuxado toi acceito com particular gratidaso pelo Banto Podre que, persuadido dos seus elleitos benteficos e depois de o ter mandado analyaar pelo Director da Pharanacia do Vaticano, formulou os seus cinceros desejos de que o producto se torne famoso - seja apreciado pelo publico coma o seu beneficio certamente merece,

J. TEDESCHI, Secretario de Estado do Vattcano)

(Traduç̧⿻)

-A compesiço do "Ferro Nuxado, $f$ tal que os seus elloitos pbysiologicos - Lherapeuticos nđ̆o podem deixar de se produzir como 6 usual na preacripcaso de productos pharmaceuticus d'esta indole.

(F. NARCISO DURIBISCHEIM, Direcior da Pharmacia do Vaticano)

Quatro milhões de pessoas | me de Dae Health Laboratotomam .FERRO NUXHDO, ries e encontra-se $\alpha$ venda annualmente. Recuse os subs- em todas as boas pharmacias titutos. $O$ genuino leva o no- $\mid$ e drogarias.

\section{Unicos depositarios no Brasil, GLOLSSOP \& C.}

MAIA, Samanta Rosa. O Vaticano em Roma recomenda ferro nuxado: discurso e análise de um anúncio de medicamento do início do século XX. Linguagem em (Dis)curso - LemD, Tubarão, SC, v. 17, n. 3, p. 419-431, set./dez. 2017. 
$\mathrm{O}$ anúncio, tendo por título "O Vaticano em Roma recomenda Ferro nuxado", traz a foto e a assinatura do Papa Bento XV, e dois depoimentos de autoridades do Vaticano (do Secretário do Estado e do Diretor da Farmácia); na sequência, apresenta um dado estatístico sem menção a qualquer pesquisa/fontes de referência atestando uma enfermidade não-nomeada, que pode ser adquirida devido a causas não mencionadas ou ser "herdada", e é caracterizada como "falta de robustez no sangue ou no sistema nervoso" (na versão norte-americana, a doença é denominada anemia). Vê-se aí a transferência de um atributo aparente (a robustez das pessoas saudáveis, mencionada na frase abaixo da frase-título da propaganda: "se você está com falta de robustez") para uma substância (chamada "robustez" que estaria presente no sangue); o dado mais exterior e imediato é tomado como explicação final [para a doença] (a aparência desejada é substancializada). Trata-se de um artifício textual cuja implicação, para o discurso, é a criação de uma necessidade fisiológica, a produção de uma carência, que se converta em necessidade de consumo.

Depois, o anúncio faz a listagem de uma série de sintomas juntamente com a indicação do remédio, frisando a diferença entre o ferro orgânico e o ferro metálico, assim como a equivalência do ferro orgânico ao "extrato de carne" (a uma quantidade de carne indeterminada), isto é, enfatizando a oposição entre $o$ natural e o fabricado/artificial/sintético. As oposições dispensam, assim, a tradição de saberes locais e familiares, que é invalidada na substituição por um saber que se quer universal; ao mesmo tempo em que esse saber, "científico", se reveste de natural, na tentativa de manter intacta a relação das pessoas, que ainda lidavam com certo sentimento de violação provocado pelas bruscas mudanças tecnológicas e urbanísticas, com um passado mais rural:

[...] o intenso surto de urbanização, trazendo para as cidades gentes sobretudo de origem rural, rompeu o contexto da família ampla e a cadeia de transmissão do conhecimento das ervas, tratamentos e processos tradicionais de cura. O lapso foi rapidamente preenchido pelos novos laboratórios químicos e, sobretudo, pela rapidez dos oportunistas em se dar conta da nova situação. (BUENO; TAITELBAUM, 2008, p. 60)

Conforme Lima (1996), que analisou práticas cotidianas, rotineiras e anônimas da sociedade carioca do século XIX relacionadas à saúde, tomando como suporte descobertas arqueológicas encontradas em escavações feitas em diversos pontos do estado, esse conhecimento popular, até então fortalecido pela realidade do número insuficiente de médicos, é combatido e alterado como consequência da "consolidação de uma ideologia da higienização". Recorde-se o episódio da Revolta da Vacina, no Rio de Janeiro, em 1904, quando o governo promoveu uma campanha sanitarista e um plano de saneamento e higienização da cidade a fim de controlar o quadro epidemiológico que assolava a população.

\footnotetext{
Entendendo que o corpo individual, enquanto sistema de comunicação, possui uma linguagem, um código, e veicula mensagens para as esferas mais amplas do corpo social, e que "um sistema de símbolos está sempre presente no comportamento social em relação ao corpo ou no comportamento do corpo em relação à sociedade", como observou Rodrigues (1986, p. 130), a implantação de uma ordem corporal foi fundamental para a construção e manutenção da ordem social do século XIX. Nesse contexto, a consolidação de uma ideologia de higienização foi uma das mais consequentes e eficazes estratégias para a sustentação do projeto vitorioso de hegemonia da burguesia. (LIMA, 1996, p. 79-80)
} 
$\mathrm{O}$ anúncio termina com uma exibição de resultados, novamente fazendo uso de estatísticas sem procedência: "milhares de pessoas têm aumentado em duas semanas a sua robustez e resistência d'uma forma surpreendente".

\section{ASSINATURA E DISCURSO RELIGIOSO COMO EFEITOS DE EVIDÊNCIA}

Mas por que associar uma figura religiosa a uma propaganda de "remédio", em 1921? Apesar de a frase-título da propaganda fazer menção ao Vaticano, não há nenhuma legenda indicando, isto é, assegurando que a personalidade fotografada é o Papa. Identifica-se o Papa pela vestimenta (a mozeta papal), pelo solidéu, pela postura com que está sentado na cadeira, que se parece com um trono, ou ainda pela assinatura (entre os rabiscos podemos ler seu nome). Mas, porque o discurso antecipava seu próprio público - e o catolicismo, era, então, a religião da maior parte da população - não havia qualquer necessidade de garantir, mediante um sinal mais explícito, o reconhecimento de que a foto estampada na página era do Papa. Isso já estava subentendido como parte da memória institucionalizada. A mera presença do Pontífice, ali inominada, em fotografia, emprestava ao produto a autoridade derivada de seu lugar nas relações de força - o lugar de autoridade máxima política, doutrinal e administrativa da religião dominante no momento: a Católica. Além disso, a publicidade aproveitava-se também, desse modo, da formação imaginária dos leitores antecipados, fazendo com que o Papa, que, para eles, ocupasse a posição de representante e detentor da verdade, fosse também o porta-voz do produto anunciado.

A fim de conferir ainda mais autoridade, e, principalmente, autenticidade a essa aprovação do Papa - para convencer até mesmo aqueles que dela pudessem duvidar - é colocada, abaixo de sua fotografia, sua assinatura. $\mathrm{O}$ gesto performativo ${ }^{2}$ da assinatura é justamente aquele que é concebido como um substituto da presença do falante preservando, mesmo na sua ausência, sua ligação de responsabilidade com aquilo que é dito. Derrida, em Assinatura Acontecimento Contexto, cita, pensando nesse tipo de estatuto da assinatura, as seguintes palavras do filósofo John Austin: "A assinatura é evidentemente necessária, não estando as enunciações escritas ligadas à sua fonte como estão as enunciações verbais" (AUSTIN, apud DERRIDA, 1991, p. 371). A assinatura, para Austin e para os leitores antecipados pelos publicitários, liga, de uma maneira não problemática, o enunciado à sua origem, porque, embora implique "a não presença atual ou empírica do signatário", parece implicar também "seu ter-estado presente num agora passado", que é, por sua vez, eternamente presente. Quanto a isso, vale citar explicitamente as palavras de Derrida:

\footnotetext{
Esta permanência geral está de algum modo inscrita, pregada na pontualidade presente, sempre evidente e sempre singular, da forma de assinatura. É essa a originalidade enigmática de qualquer rubrica. Para que a ligação à fonte se produza, é necessário portanto que se retenha a singularidade absoluta de um acontecimento de assinatura e de uma forma de assinatura [...]. (DERRIDA, 1991, p. 371)
}

\footnotetext{
${ }^{2} \mathrm{O}$ gesto performativo é um ato linguístico que não é uma descrição de um estado de coisas, mas cria um estado de coisas.

MAIA, Samanta Rosa. 0 Vaticano em Roma recomenda ferro nuxado: discurso e análise de um anúncio de medicamento do início do século XX. Linguagem em (Dis)curso - LemD, Tubarão, SC, v. 17, n. 3, p. 419-431, set./dez. 2017.
} 
O filósofo francês, no entanto, considera ingênua essa visão, porque "para funcionar, quer dizer, para ser legível, uma assinatura deve ter uma forma repetível, iterável, imitável, deve poder separar-se da intenção presente singular de sua produção." (DERRIDA, 1991, p. 371). De certo modo, o que constitui sua autenticidade mesma é a sua possibilidade de ser copiada, e, portanto, falsificada. A assinatura é constitutivamente sujeita a falha, assim como "a língua é sujeita ao equívoco" (ORLANDI, 1999, p. 37). A análise do discurso, considerando a linguagem na sua condição de incompletude, permite pensar essa repetição da assinatura como uma repetição histórica, que faz, nas palavras de Orlandi, “o irrealizado irromper no já estabelecido" (ORLANDI, 1999, p. 54). Porque a falsificação reside no íntimo de toda assinatura autêntica, uma provável assinatura falsificada - ou, ao menos, descontextualizada (isto é, adulterada pelo deslocamento) - é ainda uma assinatura, que carrega consigo, aos olhos do público, toda a autoridade da presença da sua suposta origem. É dessa condição de existência ambígua da assinatura que os publicitários do "Ferro Nuxado" se aproveitaram.

Apropriam-se também de um respeito à infalibilidade associada, na formação imaginária dos leitores, às declarações papais. O Papa, de acordo com o primeiro depoimento apresentado no anúncio, incita os consumidores, não a comprar o produto por causa de seus benefícios e qualidades, mas para que "ele se torne famoso" e "apreciado". A autoria desse depoimento é atribuída a J. Tedeschi, como sendo Secretário de Estado do Vaticano; entretanto, esse cargo nunca foi ocupado por alguém deste nome - quem o ocupava, na época de circulação deste anúncio, era o cardeal Pietro Gasparri. Já no segundo depoimento, atribuído ao diretor da farmácia do Vaticano, o que se observa é uma reiteração do mistério acerca da constituição farmacológica do produto. Diz-se apenas que "a constituição é tal", e passa-se a listar os benefícios que é capaz de produzir - sem o esforço de esclarecer uma explicação sobre como o dito remédio opera tais resultados, quase como se se tratasse de um "milagre"... Qualquer semelhança com um mistério de fé, como a santíssima trindade ou, em especial, a transubstanciação eucarística, talvez não seja mera coincidência.

Não é mera coincidência porque, na coluna direita do anúncio, já se havia dito: "Ferro é o elemento vital do sangue, e o sangue é a vida." A expressão "sangue é vida" atua, simultaneamente, em duas formações discursivas aparentemente distintas: a religiosa e a científica. Ou seja, ambas possuem reguladores diferentes do que pode ser dito ou não dito, por inscreverem-se em formações ideológicas diferentes, porém, isso não impede - é importante dizer - que seus discursos se encontrem. E não faltarão mesmo tentativas de conciliação, conforme atesta o sociólogo Robert Nisbet, em seu estudo sobre a ideia de progresso:

Durante o período que vai de 1750 a 1900 a ideia de progresso atingiu seu zênite no Ocidente, tanto em círculos quanto em acadêmicos. Era "uma" das ideias mais importantes do Ocidente e transformou-se na ideia dominante, mesmo levando-se em conta a importância crescente de outras ideias como igualdade, justiça social e soberania popular - cada uma das quais foi muito importante neste período. [...] No período com o qual estamos nos ocupando agora, também vemos surgir e se desenvolver a secularização da ideia de progresso destacando essa ideia de seu anterior relacionamento com Deus e tornando-a um processo histórico ativado e mantido por causas puramente naturais. [...] Não se pode dizer que a devoção cristã tenha desaparecido na ideia de progresso durante o século XIX. Cientistas do valor de Louis 
Agassiz, na América do Norte e filósofos eminentes como Hegel combinaram a fé na possibilidade de demonstração científica do progresso com a fé serena e manifesta do Deus cristão. [...] Comte, provavelmente o mais famoso e influente filósofo do progresso do século XIX, fundador da sociologia "sistemática", criador dessa palavra e expoente máximo da ciência, havia-se tornado um ardoroso crente no que chamava a Religião da Humanidade quando escreveu, em meados do século, sua Positive Polity - trabalho em que elabora sua utopia positivista de forma extremamente minuciosa. Acrescentou que todos os verdadeiros positivistas deveriam unir ciência e religião, adorando o Grand Etre, para cujo culto recomendava-se litanias e rituais. (NISBET, 1985, p. 181-183)

A confusão entre as duas formações discursivas é, como se verá mais adiante, proposital. Ainda que o sentido aparente e literal desse enunciado nesse contexto seja medicinal, é necessário levar em conta o interdiscurso que aí se infiltra, que é, precisamente, de outra ordem - de ordem religiosa. Consta no segmento 1419 do Catecismo $^{3}$ da Igreja Católica que a Eucaristia - o consumo do corpo e do sangue de Cristo na Liturgia Sagrada - "sustenta as nossas forças ao longo da peregrinação desta vida". Já o Catecismo (de 1905) de São Pio X, papa imediatamente anterior a Bento XV, diz, no item 623, que ela [a eucaristia] "sustenta e aumenta" a "vida da alma" e a "vida do corpo". Todos esses sentidos residem na memória constitutiva, enraízam-se como esquecimento, porque passam a trabalhar no inconsciente, sem que deixem de ser, contudo, determinantes. O efeito metafórico aí obtido ("o sangue é vida"), que confunde o discurso medicinal, biológico, e o religioso, é que gera um lugar de deslize do sentido, um lugar onde "língua e história se ligam pelo equívoco" (ORLANDI, 1999, p. 81). Esse deslize, essa brecha para a deriva, entre o científico e o religioso ocorre de um modo bastante intricado e com um propósito bastante específico, que cabe analisar aqui.

$\mathrm{O}$ uso do Papa como autoridade para respaldar um produto que se arroga de ser científico é o que desmonta essa autoridade mesma, porque a subordina a um mecanismo de construção de verdades que não é o que a constitui, e que, no fundo, lhe é contrário. Há, nisso, uma contradição: a propaganda procura valer-se de uma autoridade na mesma medida em que (implicitamente) procura desmontá-la, deslegitimá-la.

Primeiramente, porque se funda sobre o não-dito da falência do milagre. A falência do milagre é uma instância da laicização da vida moderna:

O quadro ideológico ocidental da segunda metade do século passado apresenta claros sintomas das transformações econômicas, políticas e sociais em curso [...]. Na Europa, epicentro do terremoto industrial-capitalista, os exemplos são variados. Caso particularmente notável, a Igreja Católica demonstrará ter sentido o golpe da modernidade: se aqui a República cassa grande parte do prestígio oficial eclesiástico, lá, já em 1869, é convocado o primeiro Concílio Vaticano, como uma pauta de discussões suficientemente explícita a demonstrar o tamanho e a qualidade do problema: tratava-se de pensar as novas relações entre fé e ciência. (FISCHER, 2003, p. 57)

Essa instância, porém, não está associada somente às ideologias do cientificismo e do "naturalismo" (que o próprio Papa em questão, Bento XV, caracterizara como a

${ }^{3}$ De 11 de outubro de 1992. Catecismo é o livro que é tomado como referência, por ter o aval do magistério eclesiástico, para assuntos de doutrina católica.

MAIA, Samanta Rosa. 0 Vaticano em Roma recomenda ferro nuxado: discurso e análise de um anúncio de medicamento do início do século XX. Linguagem em (Dis)curso - LemD, Tubarão, SC, v. 17, n. 3, p. 419-431, set./dez. 2017. 
"terrível praga de nosso tempo", em seu motu proprio "Bonum Sane"4), mas também às catástrofes do início do século, como a Primeira Guerra e a Gripe Espanhola, que abalaram muito a fé das pessoas - como também indica o Papa no texto citado. O milagre não viera para livrar o mundo das trincheiras e das armas, tampouco para curar os enfermos da gripe espanhola. Por conta desse último episódio, proliferaram os remédios no espaço da ineficácia da fé, que, como se via, não poupara da epidemia nem os mais devotos. E um dos resultados dessa proliferação - geralmente imprudente - de supostos remédios, foi a proliferação, igualmente imprudente, de propagandas de remédios com indicações indevidas (um mesmo remédio era destinado, por exemplo, à cura de infecções na pele, fortalecimento dos ossos, fortalecimento do sangue, tratamento de artrite e tuberculose) e prometendo resultados improváveis, que passaram a povoar os periódicos. A do "Ferro Nuxado" é apenas uma, entre tantas outras, que estampavam os periódicos do início do século XX. E nela há um peculiar mecanismo de discursivização dessa situação, que inscreve, no nível do não-dito, a falência do milagre, a anulação do poder espiritual da Igreja.

A ação curativa do milagre, comumente concebida como uma intercessão direta da divindade - da qual o Papa seria o máximo representante - sobre a saúde de um indivíduo, é transportada [deslocada] para o âmbito de uma substância mundana, ou melhor, de uma mercadoria comercializada e produzida segundo técnicas supostamente científicas. Daí que, embora a sua autoridade seja posta como evidência e aproveitada, o Papa não tem suas palavras em nenhum momento reproduzidas no anúncio. Somente palavras não bastariam mais, o antigo milagre que delas provinha já não convence. Elas não têm mais como competir, aos olhos do público cosmopolita leitor d'A Cigarra, com o poder da medicina e da fotografia.

Pelo contrário, é reproduzido, em vez delas, o depoimento do diretor da farmácia do Vaticano, que assegura, como porta-voz da ciência, que "Ferro Nuxado" é um produto cujos resultados terapêuticos são infalíveis. Mesmo na primeira citação, a de J. Tedeschi, suposto secretário de estado do Vaticano, o relato da reação do Pontífice indica que sua intuição acerca da qualidade do produto não foi suficiente para garantir que o produto tem efeitos benéficos, pois, como o anúncio nos diz, ele mandou que fosse analisado, justamente pelo diretor da farmácia do Vaticano. Há aí, portanto, uma hierarquização na qual o farmacêutico - por representar a ciência - figura em uma posição mais segura para aferir a verdade do que o Papa, que representa o discurso religioso. A soberania do Papa é, ainda, formalmente preservada, e precisa sê-lo para que sua presença na propaganda produza um efeito de evidência, mas encontra-se esvaziada de seu conteúdo específico, propriamente religioso. Torna-se oca, porque impotente e submissa a um discurso que, em última instância, a torna supérflua.

Dois modos de produção de verdade se chocam no anúncio, e o que sai vencedor é aquele que tem a pretensão de ser científico - contraditoriamente, vale dizer, às próprias opiniões do Papa Bento XV, que, seguindo a esteira de seu antecessor, Pio X, condenou veementemente o naturalismo e o cientificismo como parte da "síntese de todas as heresias" a que se chamava, então, de "modernismo", conforme ele diz na sua primeira

\footnotetext{
${ }^{4}$ Texto escrito, aliás, um ano antes da publicação do anúncio em pauta. 
encíclica, Ad Beatissimi Apostolorum, de 1914. Contudo, o anúncio não escancara esse conflito, porque seu objetivo é cercar os consumidores por todos os lados para assegurar a venda do produto. Não seria conveniente mostrar a religião como "superada" para um público ainda quase totalmente católico. Tratava-se de colher as tendências, ainda que conflitantes, do momento, a fim de atingir um resultado bastante pragmático: o sucesso comercial. Para aqueles que ainda confiavam no discurso religioso, lá estava o Papa - e no Brasil dos anos 1920 isso contemplava boa parte da população - para aqueles que, ao menos em assuntos de saúde - em especial depois da Gripe Espanhola -, priorizavam a medicina, lá estava o farmacêutico. Para ambos e para todos os outros, lá estava também a evidência dos números ("quatro milhões de pessoas tomam Ferro Nuxado"). A ideologia capitalista aliava-se, portanto, à ideologia cientificista, sem deixar de aproveitar-se da ideologia religiosa, que se guiava pela autoridade do Papa, para construir seus discursos e produzir efeitos de evidência. E os três tipos de evidência produzidos: evidência de autoridade, evidência científica e evidência numérica, se reuniam para assegurar a persuasão dos leitores, que deveria transformá-los em consumidores do "Ferro Nuxado".

Vê-se, aí, um outro modo, mais profundo ainda, de dessacralização, em que a autoridade religiosa é desmontada. Além de ter seus dons sobrenaturais substituídos pela ação de um dito "remédio" e de ter sua confiabilidade sobrepujada por a de um farmacêutico (a falência do milagre), a imagem de seu símbolo máximo - o Papa - está submetida a uma finalidade mercadológica corriqueira em uma revista, em meio a anúncios de perfumes, de sabão e de supositórios.

\section{CONSIDERAÇÕES FINAIS}

Neste trabalho tentou-se expor, assim como exercitar, de maneira prática, os conceitos apresentados por Eni Orlandi especialmente em Análise do discurso: Princípios e procedimentos (1999). Reitera-se que a opção por adotar esse livro como referência principal deu-se por se considerar que, nele, a autora explicita as noções básicas que compõem o dispositivo teórico da Análise do Discurso sem perder de vista o corpus de análise como resultado de uma construção do pesquisador. Assumindo-se a posição de analista, investigou-se o anúncio publicitário de um remédio, datado de 1921, com vistas a refletir sobre as ideologias subjacentes nesse texto. No anúncio do Ferro Nuxado, apontou-se a materialização linguística, em código escrito e imagens, e histórica, da ideologia progressista, positivista e cientificista dominante ainda na década de 20 (um contraste com o marco da década, que foi o evento da Semana de Arte Moderna), atravessada, ou apoiada, ainda, pela ideologia religiosa.

O contexto descrito por Nisbet, citado anteriormente, como se viu, parece compatível com os discursos publicitários sobre remédios veiculados em periódicos brasileiros. Merece destaque, entretanto, a menção à permanência dessas ideologias nas décadas seguintes a 1900.

A metáfora do ferro e do sangue como vida, do anúncio analisado, relacionada à Liturgia Sagrada da Igreja Católica, à religião, surge como efeito a favor de outro 
discurso, o medicinal, mais especificamente, o científico. A infinidade de aplicações potenciais atribuídas ao remédio indica o apelo ao imediatismo, à solução instantânea, remetendo ao avanço tecnológico, ao multifuncionalismo e à rapidez das máquinas, ao "maquinarismo". O recurso é o mesmo utilizado no anúncio, por exemplo, do "Cinto radio-activo do Dr. Wood", "(único oficialmente reconhecido)", apresentado como "A MAIOR DESCOBERTA DO SÉCULO!", em letras garrafais, a solução para os doentes desenganados que já experimentaram todos os medicamentos possíveis sem obter resultado. A diferença, contudo, reside na data de veiculação dos anúncios: esse é de 1909, enquanto aquele é de 1921!

Finalmente, compreendidas as dimensões linguística e histórica do discurso, e que “o discurso, por princípio, não se fecha. É um processo em curso" (ORLANDI, 1999, p. 71), espera-se ter contribuído para a consciência do sujeito a respeito da multiplicidade de representações possíveis do discurso do século XX e do discurso em geral, e, assim, ter fornecido meios para que o leitor organize as suas representações sobre esse tempo e reflita sobre a continuidade dos discursos no seu próprio tempo.

\section{REFERÊNCIAS}

A MAIOR DESCOBERTA DO SÉCULO! A Imprensa, Rio de Janeiro, p. 4, 17 out. 1909. Disponível em: <http://bndigital.bn.gov.br/hemeroteca-digital/>. Acesso em: 20 dez. 2016.

BUENO, E.; TAITELBAUM, P. Vendendo saúde: história da propaganda de medicamentos no Brasil. Brasília: Agência Nacional de Vigilância Sanitária, 2008. Disponível em:

<http://www.anvisa.gov.br/propaganda/vendendo_saude.pdf>. Acesso em: 02 nov. 2013.

CRUZ, H. de F. São Paulo em papel e tinta: periodismo e vida urbana - 1890-1915. São Paulo: EDUC; FAPESP; Arquivo do Estado de São Paulo; Imprensa Oficial SP, 2000.

DERRIDA, J. Assinatura, acontecimento, contexto. In: . Margens da Filosofia. Tradução de Joaquim Costa, António M. Magalhães. Campinas, SP: Papirus, 1991.

FISCHER, L. A. Parnasianismo brasileiro: entre ressonância e dissonância. Porto Alegre: EDIPUCRS, 2003.

LIMA, T. A. Humores e odores: ordem corporal e ordem social no Rio de Janeiro, século XIX. História, Ciência, Saúde, Manguinhos, v. 2, n. 3, p. 44-96, 1996.

NISBET, R. História da ideia de progresso. Tradução: Leopoldo José Collor Jobim. Brasília: Editora Universidade de Brasília, 1985.

ORLANDI, E. P. Texto e discurso. Organon, Porto Alegre, v. 9, n. 23, p. 111-118, 1995. Análise de discurso: princípios e procedimentos. Campinas: Pontes Editores, 1999.

A análise de discurso em suas diferentes tradições intelectuais: o Brasil. In: SEMINÁRIO DE ESTUDOS EM ANÁLISE DE DISCURSO, 1., 2003, Porto Alegre. Anais... Porto Alegre: UFRGS, nov. 2003, p. 10-13. 1 CD-ROM.

A materialidade do gesto de interpretação e o discurso eletrônico. In: DIAS, C. Formas de mobilidade no espaço e-urbano: sentido e materialidade digital [online]. Série e-urbano. v. 2, 2013. Disponível em: <http://www.laberurb, unicamp.br/livroEurbano/LaboratóriodeEstudosUrbanos>. Acesso em: 18 fev. 2017.

MAIA, Samanta Rosa. O Vaticano em Roma recomenda ferro nuxado: discurso e análise de um anúncio de medicamento do início do século XX. Linguagem em (Dis)curso - LemD, Tubarão, SC, v. 17, n. 3, p. 419-431, set./dez. 2017. 
ANEXO: VERSÃO EM INGLÊS DO ANÚNCIO PUBLICADO PELO REVISTA A CIGARRA

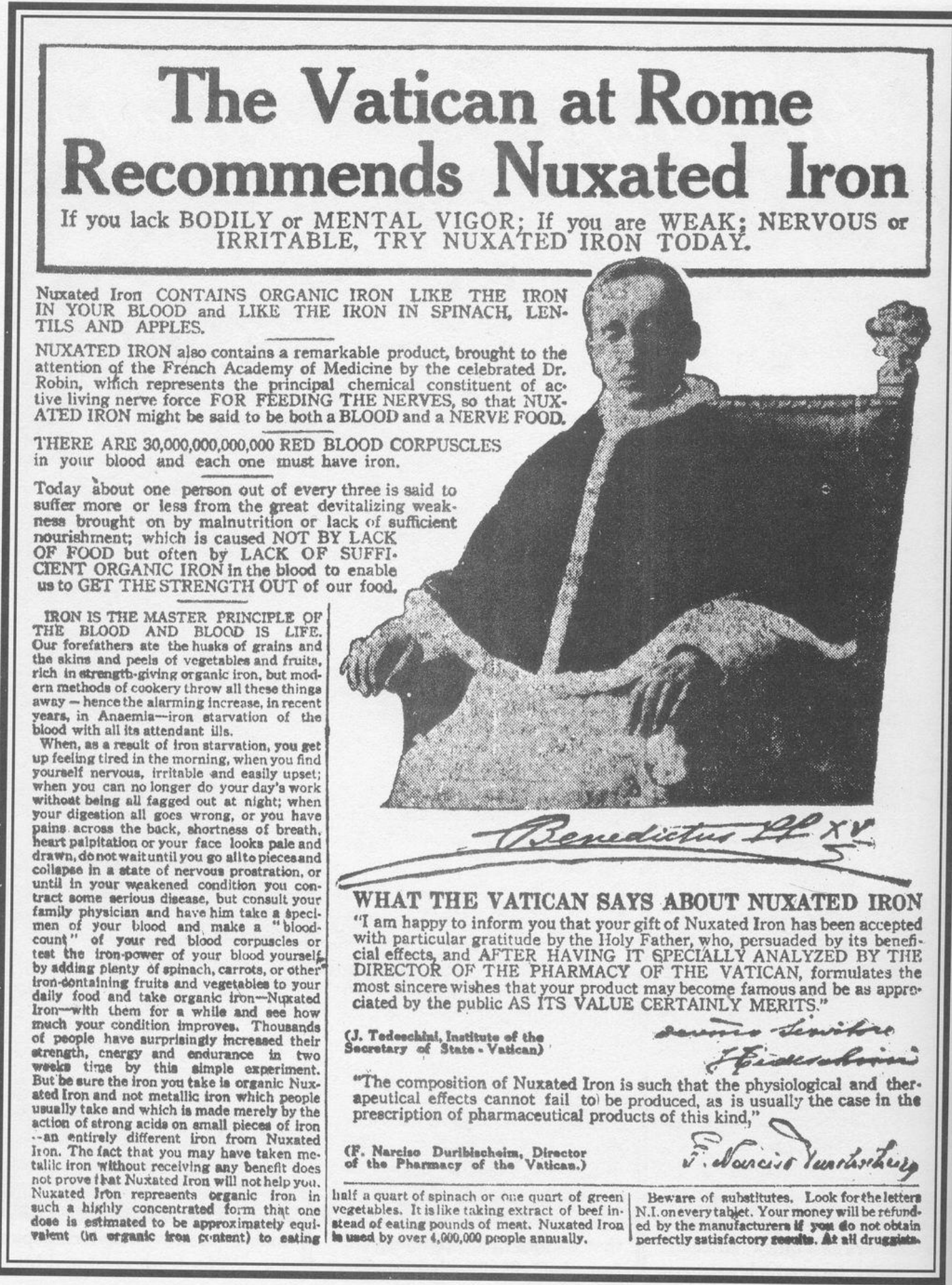

Fonte: Google Imagens.

MAIA, Samanta Rosa. 0 Vaticano em Roma recomenda ferro nuxado: discurso e análise de um anúncio de medicamento do início do século XX. Linguagem em (Dis)curso - LemD, Tubarão, SC, v. 17, n. 3, p. 419-431, set./dez. 2017. 
Recebido em: 12/04/17. Aprovado em: 28/09/17.

Title: Vatican in Rome recommends Nuxated Iron: discourse and analysis of an early 20th century drug advertisement

Author: Samanta Rosa Maia

Abstract: This work refers to the theory of Discourse Analysis practiced by Eni Orlandi and analyzes a drug advertisement, entitled The Vatican in Rome recommends Nuxated Iron, published in a great circulation magazine in the early twentieth century. The aim of the work was to bring to light the ideologies underlying the language of advertising in the early twentieth century, and at the same time to provide a practical and didactic example of analysis that would enhance the linguistic, ideological and, especially, historical aspects of discourse. Thereunto, the methodology adopted was analytical, applied to a corpus consisting of a single text and based on the concepts mainly presented by Orlandi in the work Discourse Analysis: Principles and Procedures (1999).

Keywords: Discourse. Advertising. 20th Century.

Título: Vaticano en Roma recomienda hierro nuxado: discurso y análisis de un anuncio de medicamento del inicio del siglo XX

Autora: Samanta Rosa Maia

Resumen: Este trabajo adopta cómo referencia teórica el Análisis del Discurso de filiación francesa, practicada por Eni Orlandi, y propone el análisis de un texto titulado $O$ Vaticano em Roma recomenda Ferro Nuxado [Vaticano en Roma recomienda hierro nuxado], publicado en una revista de grande circulación del inicio del siglo XX. El objetivo de trabajo fue traer a la luz las ideologías subyacentes al lenguaje publicitario en el inicio del siglo XX, y al mismo tiempo, suministrar un ejemplo práctico y didáctico de análisis, que despegase los aspectos lingüístico, ideológico y principalmente histórico del discurso. Para ello, la metodología adoptada fue analítica, aplicada a un corpus constituido de un solo texto y basada en los conceptos presentados por Orlandi, principalmente en el trabajo Análise de discurso: princípios e procedimentos (1999).

Palabras-clave: Discurso. Publicidad. Siglo XX.
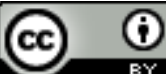

Este texto está licenciado com uma Licença Creative Commons Atribuição 4.0 Internacional.

MAIA, Samanta Rosa. 0 Vaticano em Roma recomenda ferro nuxado: discurso e análise de um anúncio de medicamento do início do século XX. Linguagem em (Dis)curso - LemD, Tubarão, SC, v. 17, n. 3, p. 419-431, set./dez. 2017. 